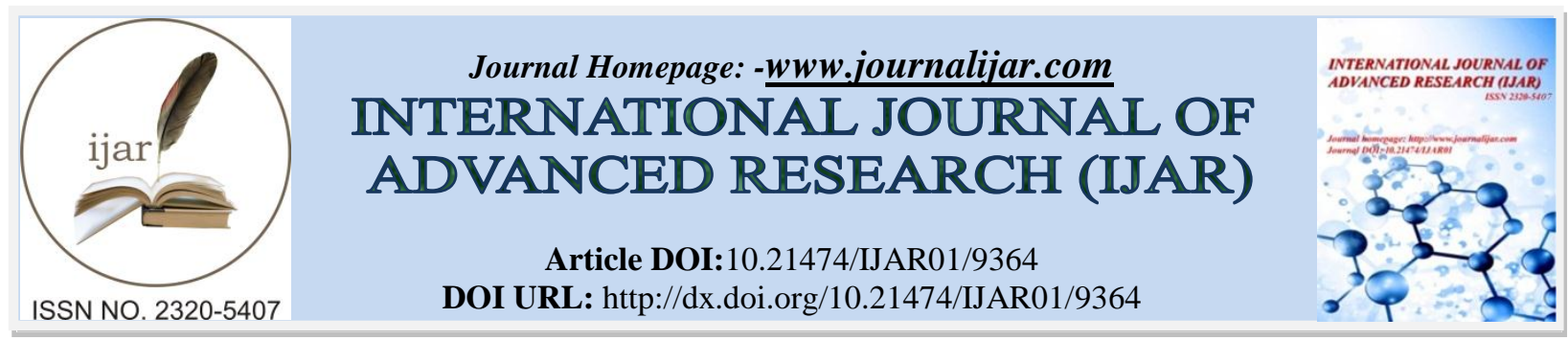

RESEARCH ARTICLE

\title{
DESIGN AND ANALYSIS OF HYDRAULIC POWERPACK AND PUMPS.
}

\section{Prof. Rahul R. Patil ${ }^{1}$, Mr. Virendra P. Patil ${ }^{2}$, Mr.Shubham S. Tashildar ${ }^{2}$ and Mr.Samarth G. Gaikwad ${ }^{3}$.}

1. Assistant Professor, Mechanical Engineering Dept., PVPIT, Sangli-Tasgaon Road, Budhgaon, Sangli, Maharashtra, India 416304.

2. U.G. Students of Mechanical Engineering, PVPIT, Sangli-Tasgaon Road, Budhgaon, Sangli, Maharashtra, India 416304.

3. U.G. Students of Mechanical Engineering, D.K.T.E Society's T.E.I Ichalkaranji, Kolhapur, Maharashtra, India 416115.

\section{Manuscript Info}

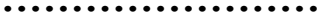

Manuscript History

Received: 10 May 2019

Final Accepted: 12 June 2019

Published: July 2019

Key words:-

ANSYS, Cycle time, Production efficiency, Productivity, Semiautomatic, VMC.

\section{Abstract}

This paper is about design and development of hydraulic system for clamping of workpiece on Vertical Machining Center (VMC). Clamping system plays vital role in any manufacturing system it provides good clamping and also increases the production efficiency.so we made a device which overcome the drawbacks of manual clamping and provide safe clamping system. This operated on hydraulic principle Pascals law. Using this we made hydraulic clamping system which semi-automatic type clamping system. Which increase productivity and reduce the cycle time of product. We also analyze the component on ANSYS 16 software for various clamping load on component.

Copy Right, IJAR, 2019,. All rights reserved.

\section{Introduction:-}

Our Project is to design and analysis of hydraulic power pack and pump for clamping and de-clamping. Basically, it depends upon the hydraulic system. The hydraulic system works on the principle of pascal's law which says that the pressure in an enclosed fluid is uniform in all the direction. From using the above hydraulic principle, we design the hydraulic power pack for clamping and de-clamping. Hydraulic power packs are stand-alone devices as opposed to a built-in-power for hydraulic machinery. Some power packs are large, stationary units and others are more portable. Since we design the hydraulic power pack which is suitable as well as portable for the above application. Mainly Hydraulic power pack contains some components like motor, pump, control valves, and some auxiliary sections. Most of the industrial hydraulic power pack uses the Vane, Gear and Piston pumps and other pumps are used for Lubricating purpose the standard parts required for hydraulic unit is selected from the standard catalog. After design we implement this system in actual machine finding out various process parameters for the workpiece clamping

\section{Objective}

The project objective describes the project's outcomes, intended and direct short- and medium-term effect on the targeted goals.

1. To analyze effect of various force on differential casing using ANSYS 16.0 software.

2. We need to observe the wear rate, heat dissipation, efficient operation about power transmission from motor to pressure creating element i.e. Gear pump. Practical problems like leakage problem, friction between parts.

3. To prepare a device that increases the productivity.

Corresponding Author:-Prof. Rahul R. Patil.

Address:-Assistant Professor, Mechanical Engineering Dept., PVPIT, Sangli-Tasgaon Road, 
4. To minimize operations time per product.

\section{Problem Definition}

1. In VMC (vertical machining center) whenever we clamping the job manually there are some drawbacks

2. Less Accuracy (Clamping Force) - Whenever human being applies the force manually on the clamping device it will changes time to time or human to human. Due to these the job/workpiece clamping accuracy is decreases. The human clamping force does not constant.

3. Feedback Loop - When the workpiece clamped on the VMC, the machine and worker both does not get clamping indication i.e. (job is clamped or not).

4. Time Consuming - Whenever the manual clamping is carried out it takes a lot of time for clamping and declamping. And also analyzing the clamp is fixed or not.

5. Surface Finish - When the manually clamping is carried out we does not get required surface finish.

6. Others - Whenever the manually clamping is carried out on VMC machine, if workpiece will not be clamped perfectly it will reduce the accuracy of other process that will done on VMC machine.

For manually clamping we always required qualified / skilled labor. From above problems, Maintenance as well as operating cost increases. So, such all problems related to manually clamping, we will be designing an automatic clamping system for that we will moving towards hydraulic system this more accurate also widely used in industry. So, our work is to design hydraulic power pack unit for clamping and de-clamping of workpiece on VMC machine.

\section{Literature View}

N. P. Maniar et. al., [1] reviews locating and clamping considerations, taxonomy of fixture planning \& design, also shows an example of fixturing alternatives and characteristics for three types of fixtures i.e. Modular fixturing, General Fixturing, Permanent fixturing. They provide a system view of fixture planning and Design for data \& information exchange also gives detailed discussion on CAFD- Computer Aided Fixture Design.

O.J Bakker et al- [2]-This paper analysis the latest studies in the field of achieve fixture design and its relationship with flexible clamping and reconfigurable fixture system. In this paper reveals that performance and flexibility are the driver behind the different fixturing contact that have been proposed. Helps to improve accessibility.

Sunny N Shahane et al- [3]-This fixture was designed and built to hold support and locate fire tube boiler plate to ensure that it is drilled with accuracy. Which can help in improving productivity and time? This automation reduced the human effort also the design enabled vibration free operation. It increased the productivity and reduced the cycle time of 1 hour to 15 times.

Sridharkeshava K B et al- [4]-This paper gives a brief introduction to the general and classic principles of jigs and fixtures Design for Clamping operation. The workpiece location clamping stability under dynamic machining and frictional conditions at the interface between jigs and fixtures elements and workpiece are taken into account-1. Manufacturing considerations 2. Clamping location, pool guiding and workpiece and mounting.

K.M Viramgama et al- [5]-This paper will give brief overview if about the 3-2-1 Locating principle to design the fixture for complex parts and other clamping principle. From the study we can conclude that for designing the fixture the geometry method 3-2-1 principle is very useful for the complex component.

Srinivas R et al - [6] -A hydraulic system is a group of hydraulic elements arranged in an order and using these hydraulic element powers is transmitted using a confined liquid i.e. Oil. Hydraulic power units are drive system for hydraulic machines.

\section{Component Details}

The component is Bajaj ape differential casing. A differential is device which used for obtaining two different speeds of rear wheels of vehicles while turning. This split type construction having two parts of casing which are attached by means of bolting. The fig no.1 shows the differential casing one part. The component is made up of grey cast iron (ASTM48). This is made by sand casting process. The differential is also known as secondary gearbox of vehicles. 
Operations to be performed on differential casing are drilling of four holes and tapping this hole on VMC machine. For that we develop hydraulic clamping system to increase the accuracy of production and for reduction of cycle time.

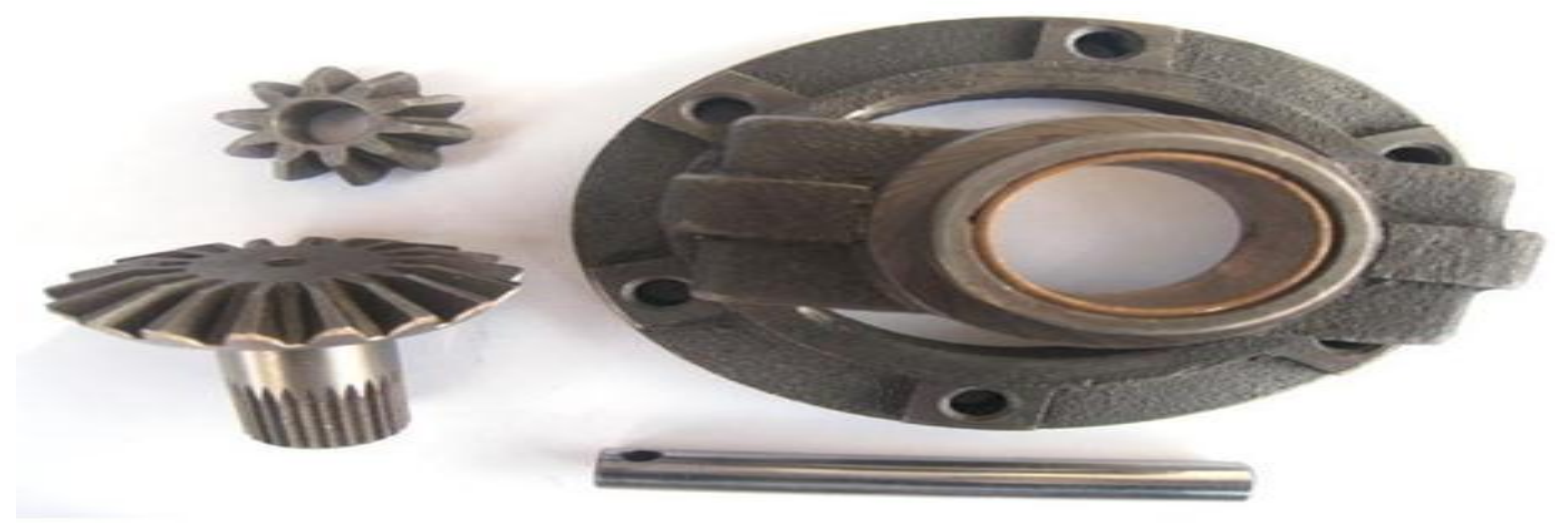

\section{Hydraulic Circuit}

Figure no 1:-Bajaj APE differential casing parts.

A hydraulic circuit is a system which has different interconnection between many hydraulic parts in which the hydraulic liquid is flow and generate power. This power is used to achieve a specific function resulting in work being performed. Before the hydraulic circuit can be designed, the following things must be defined

1. The type and number of each type of hydraulic actuator to be used on fixture.

2. The operating pressures required.

3. The sequence of operation.

4. Type of control required.

The circuit comprises the following components:

1. Active components-Hydraulic power pack

2. Transmission lines- Hydraulic pipes

3. Passive components- Hydraulic cylinders

Hydraulic pump is used of output 1.395 LPM. Hydraulic Pump is a device used to impart motion and pressure to the fluid in a hydraulic circuit. Pump is driven by 3 phase, $1 \mathrm{hp}$ electric motor to create flow. Pump that creates flow pushes against the piston of a hydraulic cylinder.Directional control valve is one of the most fundamental parts in hydraulic circuit. They allow fluid flow into different paths from one or more sources. Here double solenoid, spring centered and center open type D.C. valve is used. The valve is controlled by an electric current through a solenoid. At center position pressure line is connected to tank line and motor is unloaded. Due to this one can connect or disconnect quick disconnect coupling at center position. Cylinders are linear actuation devices that are typically used to keep a work piece stationary or move work piece into position. They provide axial clamping force proportional to the hydraulic pressure applied. Hydraulic clamp used is of $2.22 \mathrm{KN}$ force @ $15 \mathrm{Bar}$, piston diameter is of $45 \mathrm{~mm}$, Stroke is 58. It is important when designing a circuit that all devices including fittings, hoses, valves, tubing have a working pressure compatible with circuit pressure.

Never exceed the maximum operating pressure of any device. If the system flow requirement for clamp time is established with in the restrictions of the largest device, the addition of a flow control will be required to prevent over driving the smaller devices. Hydraulic circuit is shown in fig no.2 


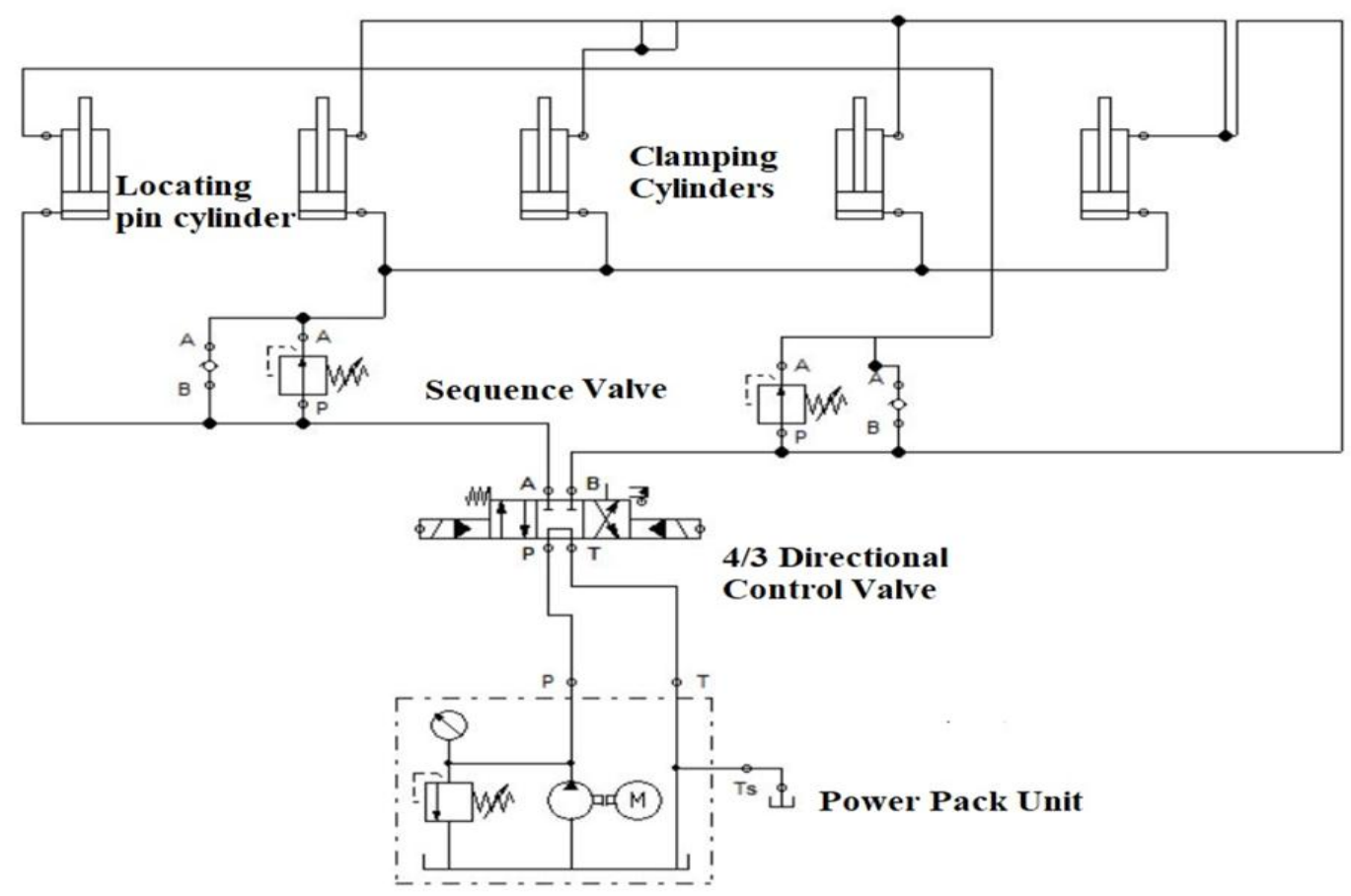

Design

Figure no2:-hydraulic circuit diagram with different component

Every mechanical system having some design procedure and we all know which are important things that we want to design for system and this design gives satisfactory work according to calculations. Hydraulic system consists of many parts but from that we want to calculate some important parameter like

1. Hydraulic cylinder

2. Flow rate/ discharge of system

3. Tank capacity

Now for designing of our system we required some basic information, so we have following information.

1. Required Clamping time $=4 \mathrm{sec}$

2. Required Clamping force $=225 \mathrm{~kg}$

3. Operating pressure $=14$ bar Pump and motor

\section{Design of Hydraulic Cylinder}

Force $=$ pressure $*$ area

Hydraulic cylinder diameter $(\mathrm{D})=45 \mathrm{~mm}$

Clamping force $=2226.60 \mathrm{~N}$

Stroke length $(\mathrm{l})=1.3 \mathrm{~d}=58.5 \mathrm{~mm}$

Length of cylinder $(\mathrm{L})=2 \mathrm{~d}=90 \mathrm{~mm}$

\section{System Flow Rate (Q)}

Flow $\operatorname{rate}(\mathrm{Q})=\frac{\text { volume }}{\text { time }}=1.395 \mathrm{LPM}$

\section{Tank Capacity}

\section{Heating Calculations}

Tank capacity $=4 *$ flow rate $=4 * \mathrm{Q}$

Tank capacity $=10$ lit.

$$
\begin{aligned}
\mathrm{HP} & =\frac{\text { pressure }(P S I) * \text { flow rate }(L P H R)}{1714} \\
& =\frac{203.505 * 0.368}{1714}
\end{aligned}
$$




\section{$\mathrm{HP}=0.04375 \mathrm{BTU} / \mathrm{Hrs}$.}

\section{Finite Element Analysis (Fea) Of Component}

Finite element analysis (FEA) is a computerized method for predicting how a product reacts to real word forces, vibrations and other physical effects. Finite element analysis shows whether a product will break, wear out or work the way it was designed. Here we divide the component into small sizes known as element and collective element on the model form mesh. The computer analyses the element and shows collective result. The computer solves by the computational method provided. FEA analysis is done on ANSYS 16.0

The test results showed that the deflection was within permitted limit or not. For checking whether static and dynamic forces acting over the component are within acquired such that it will provide some of flexibility to it without causing damage to some software are used for it to simulate that designed component are safe or not also whether further improvement is needed. This is done by using ANSYS 16.0 software.

Table no 1:-Bajaj ape differential casing material

\begin{tabular}{|l|l|l|}
\hline Sr no & Parameter & value \\
\hline 1 & Material & Grey cast iron \\
\hline 2 & Nominal composition & C 3.4, si1.8, Mn 0.5 \\
\hline 3 & Form and condition & cast \\
\hline 4 & Yield strength (tensile strength) & 330 MPA \\
\hline 5 & Elongation & 0.5 \\
\hline 6 & Hardness & 260 BHN \\
\hline
\end{tabular}

\section{Meshing}

As for analysis whole element is divided into number of parts called as nodes. These nodes are joined to each other to form elements. The process of joining these nodes is called as meshing. We can choose auto mesh mode. This meshing is shown in following figure no 3 .

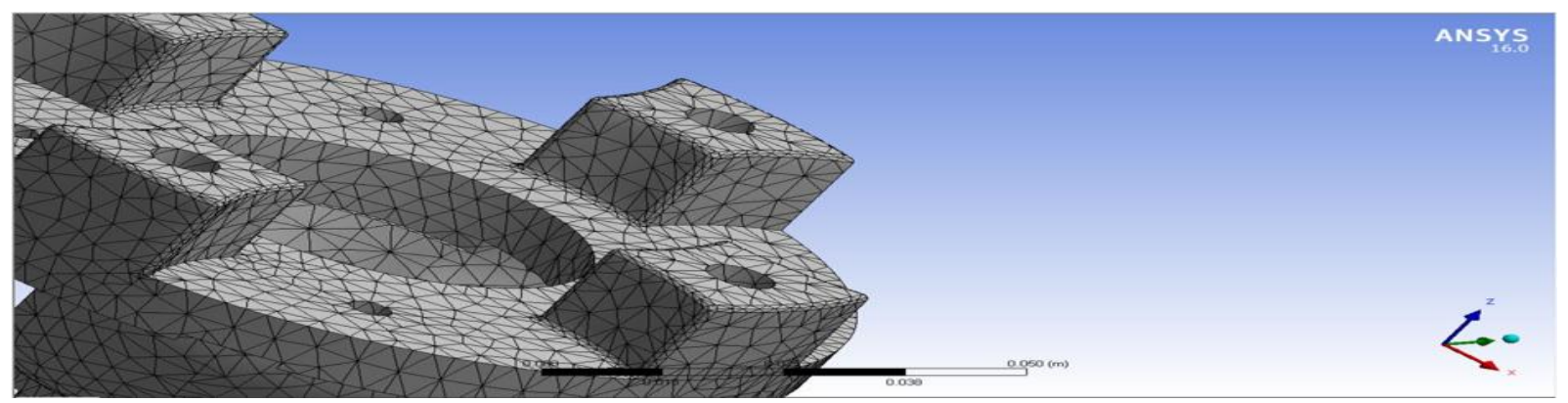

Fig no 3:-Meshing view of component

\section{Fixed Constraint}

In this we fix the various parts of the component so that they are fix at time of applications of force following figure shows the fixed part of component which is shown in fig no 4 by blue color

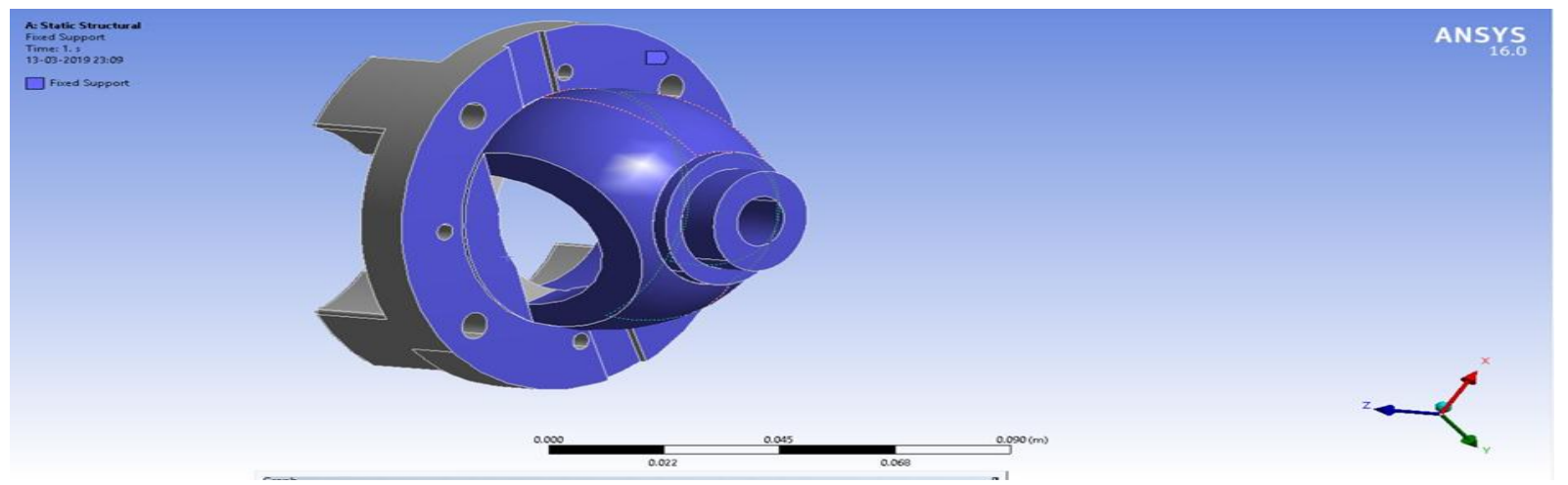

Figure no 4:-Applying fixed constraint on component 


\section{Force Constraint}

In this we apply force on component also we define the direction of the force. This shown in fig no. 5 by red color. We apply forces on all the four surfaces.

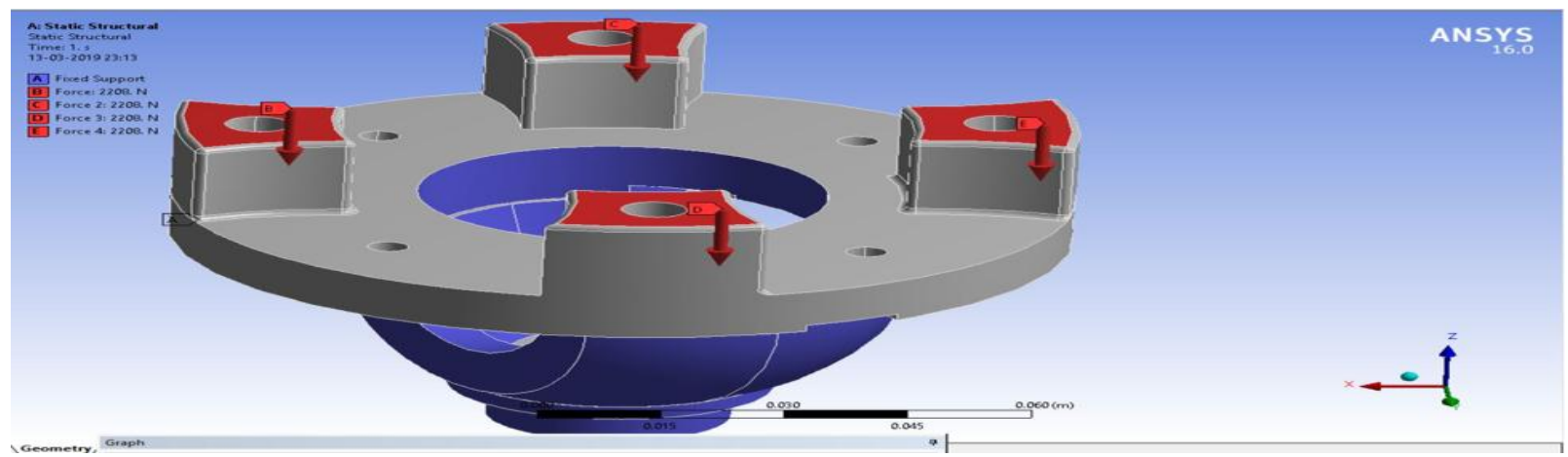

Figure no 5:-Applying force on component

\section{Stress}

After applying force on the component there is tremendous amount of stress is generated which effect on casing which is shown in fig no. 6 and the results obtained from this stress value is shown in table no 2.

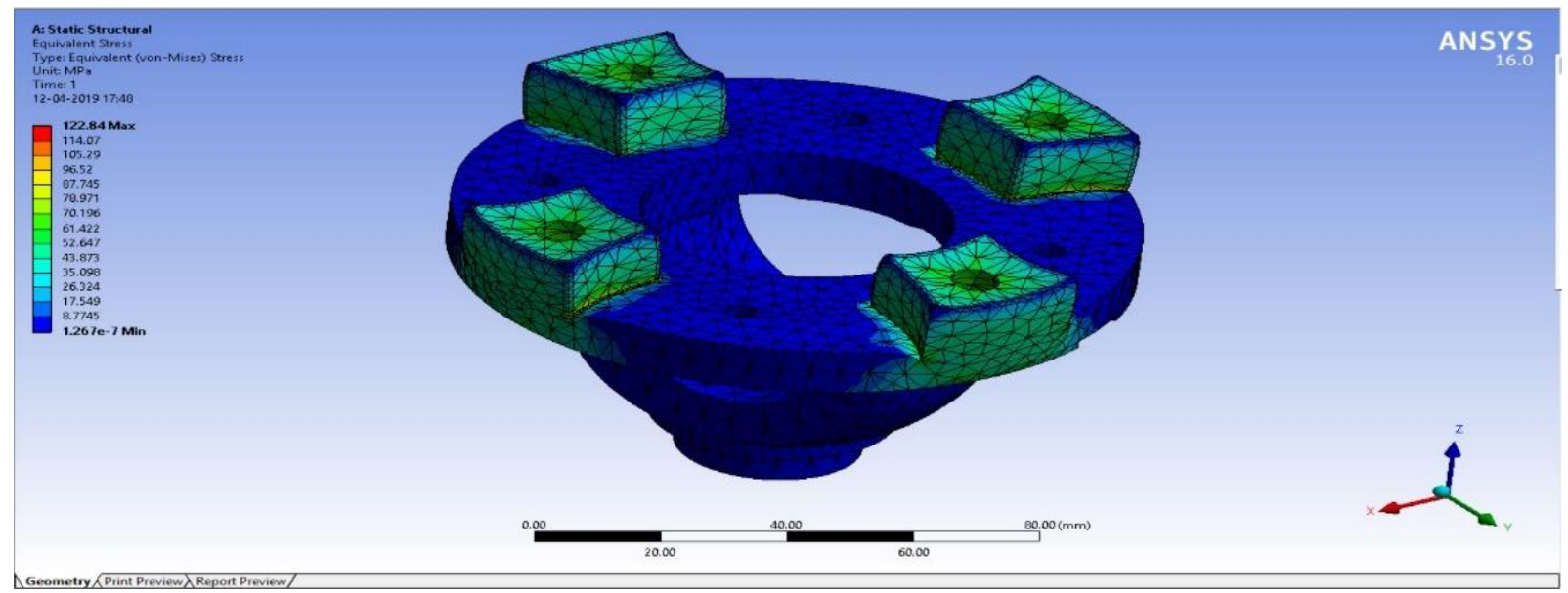

Figure no 6:-Stress generated in the component

Table no 2:-Results from stress value

\begin{tabular}{|l|l|}
\hline Max. stress of material & $330 \mathrm{MPA}$ \\
\hline Max. stress developed & $122.8 \mathrm{MPA}$ \\
\hline Factor of safety & 2.687 \\
\hline
\end{tabular}

\section{Strain}

Strain is property which shows how much component is elastically strong this result is shown table no. 3 and the generated strain in the component is shown in fig no.7. 


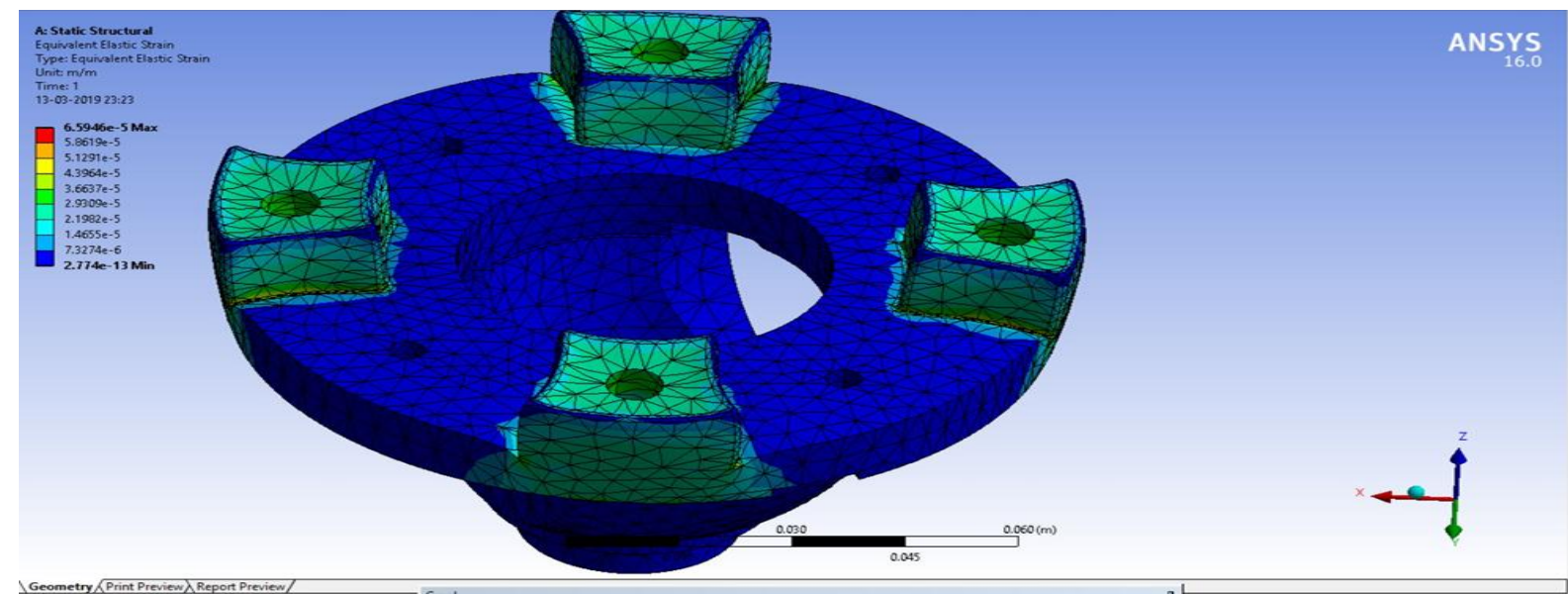

Figure no 7:-Strain generated in component

Table no 3:-Strain value

\begin{tabular}{|l|l|l|}
\hline Parameter & In meter $(\mathrm{m} / \mathrm{m})$ & In millimetre $(\mathrm{mm} / \mathrm{mm})$ \\
\hline Strain developed & $6.595 \mathrm{e}-5$ & 0.06595 \\
\hline
\end{tabular}

\section{Deformation}

Deformation means change in the shape or size of the component due to applied force which show in the following fig no 8 and the value of deformation shown in table no 4.

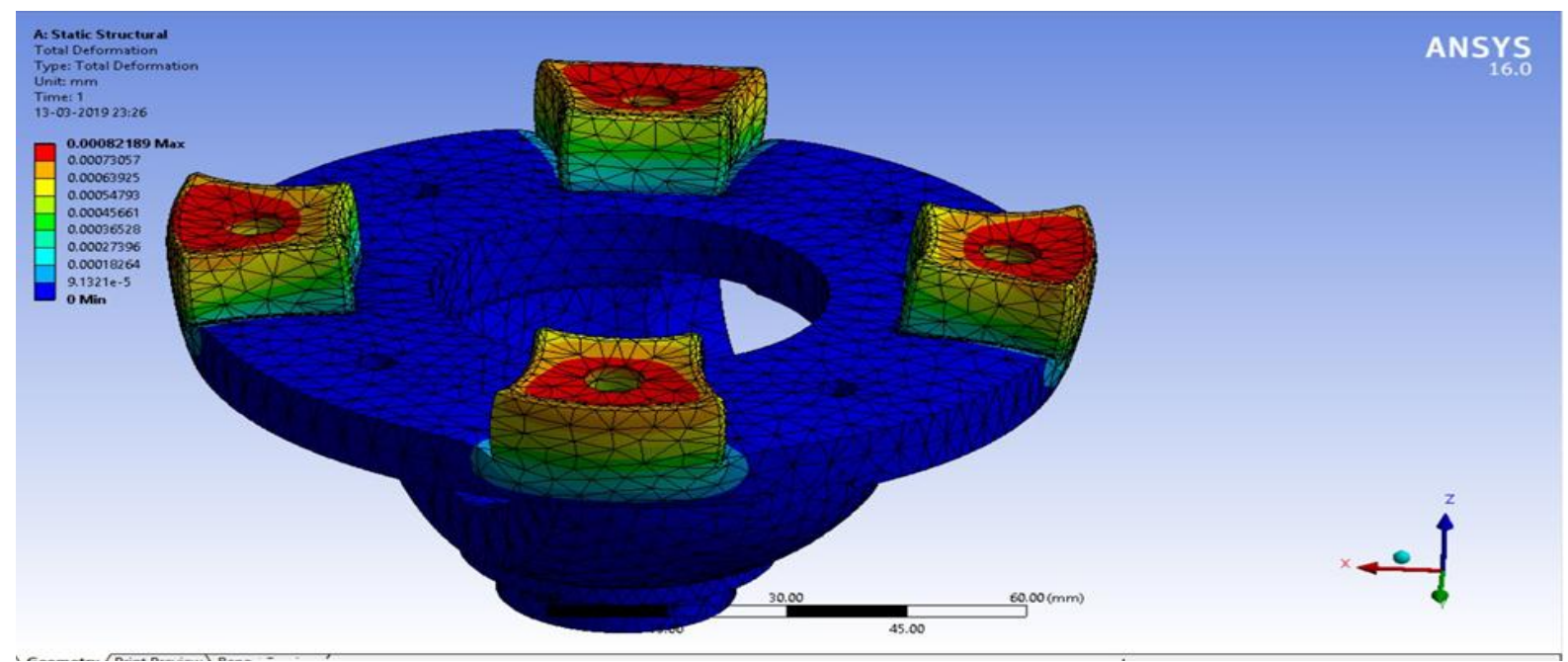

Figure no 8:-Deformation in the component

Table no 4:-Result of deformation

\begin{tabular}{|l|l|l|}
\hline Parameter & In meter $(\mathrm{m})$ & In millimetre $(\mathrm{mm})$ \\
\hline Total deformation & $8.296 \mathrm{e}-7$ & 0.0008296 \\
\hline
\end{tabular}

In the same we apply different force applied on the casing and we observe the various effect on the differential casing the various value of stress and deformation is give below form that all we can choose $225 \mathrm{~kg}$ force because it is recommended by industry but according to our analysis, we also can use force of $250 \mathrm{~kg}$. The value of various deformations and stress are given in table no 5. 
Table no 5:-Effect of various forces applied on component

\begin{tabular}{|l|l|l|}
\hline Force applied $(\mathrm{kg})$ & Stress developed (MPA) & Total deformation $(\mathrm{mm})$ \\
\hline 225 & 122.8 & 0.0008256 \\
\hline 250 & 150.64 & 0.0009128 \\
\hline 500 & 301.27 & 0.0018 \\
\hline 750 & 451.91 & 0.0027 \\
\hline 1000 & 602.25 & 0.0136 \\
\hline
\end{tabular}

\section{Result and Discussion:-}

\section{Calculations for Manually Fixture}

Time required

Total number of shifts $=1$

Total working time in shift is $7 \mathrm{hr} 30 \mathrm{~min}$ i.e. $450 \mathrm{~min}$ (30 min utilized in lunch break)

Total number of finished products in each shift $=45$

Processing time $=$ machining time + loading and unloading time + part travel time (from pallet to fixture or vice versa) Now,

1. Machining time (for 4 holes) $=5 \mathrm{~min}$

2. Loading time $=2 \mathrm{~min}$

3. Unloading time $=2 \mathrm{~min}$

4. Part travel time $=1 \mathrm{~min}$

Therefore, total processing time $=10 \mathrm{~min}$

\section{Cost of operations}

Cost of finished product= Rs 10/- part

Cost of finished product per shift $=45 * 10=\mathrm{Rs} 450 /$ -

There are 26 days of working in one month (4 days holiday for breakdown maintenance)

\section{Therefore}

Annual production cost of finished products $=450 * 12 * 26=$ Rs $1,40,400 /-$

\section{Calculations for Hydraulic Clamping}

\section{Time required}

Total processing time includes machining time, clamp actuation and de-actuation time and part travel time. According to standard specification of cylinder, clamping will actuate in $5 \mathrm{sec}$. Therefore

Processing time $=$ machining time + clamping time and de clamping time + part travel time Now,

1. Machining time $(4$ holes $)=5 \mathrm{~min}$

2. Loading time $=4 \mathrm{sec}$

3. Unloading time $=4 \mathrm{sec}$

4. Part travel time $=1 \mathrm{~min}$

Therefore,

Total processing time $=6 \min 8 \mathrm{sec}$

Saving time per part $=3 \mathrm{~min} 52 \mathrm{sec}$

Now,

Total number of products produced per shift $=65$

Increase in number of products $=65-45=20$

Increase of production part $=20$

Cost of operations

Cost of finished product $=$ Rs 10/- part 
Cost of finished product per shift $=$ Rs $650 /-$

Annual cost of finished product $=$ Rs 2, 02,800 /-

Annual increase in production cost of finished part $=2,02,800-1,40,400$

Increase in profit $=$ Rs $62,400 /$ -

Table no 6:-Comparison between existing system and newly employed syste

\begin{tabular}{|l|l|l|}
\hline Parameter & Manually system & Hydraulic system \\
\hline Loading and unloading time & $2 \mathrm{~min}$ & $4 \mathrm{sec}$ \\
\hline Cycle time & $10 \mathrm{~min}$ & $6 \mathrm{~min} 8 \mathrm{sec}$ \\
\hline Finished part/ shift & 45 & 65 \\
\hline Annual cost of finished part & Rs $1,40,400 /-$ & Rs 2,02,800/- \\
\hline Productivity & Less & Increases \\
\hline
\end{tabular}

\section{Conclusions:-}

Major benefits of this project to company

1. By using this fixture cycle time reduces by 3 minutes. Cycle time on manual fixture was 10 min and on hydraulic fixture is $6 \mathrm{~min} 8 \mathrm{sec}$ because loading and unloading time is reduced by $50 \mathrm{sec}$.

2. 45 products are produced per shift on manually operated fixture and 65products are produced on hydraulic fixture. With the help of this fixture extra 20 parts per shift are produced.

3. By using this system, we save Rs 62400/- per annual.

4. All the values of deformation and von misses stress calculated with ANSYS software is comparatively lower than standard values and hence, we can conclude that design is safe.

5. The proposed clamping system provides the repeatability and high productivity, and also offers a solution which reduces workpiece distortion due to clamping and machining forces.

6. The person from industry will definitely satisfied with the performance of fixture for machining of differential casing because of more benefits compared with conventional process with accuracy and repeatability on VMC

\section{Reference:-}

1. N. P. Maniar, D. P. Vakharia, "Design \& Development of Fixture for CNC -Reviews, Practices \& Future Directions" International Journal of Scientific \& Engineering Research Volume 4, Issue 2, February-2013 ISSN 2229-5518.

2. J Bakker, T N Papastasthis, A A Popov, S M Ratchev. "Active fixturing: literature review and future research directions". In proceeding International journal of production research, Vol 00, Month 2011.

3. Sunny N Shahane, Amol D Lokhande, Shanjivani R Bhosale, Neha S Shirodkar. "Design and Development of clamping fixture for Drilling of Boiler Tube Plate". In proceeding International journal of current engineering and technology, Issue-4 March 2016.

4. Sridharkeshava K B. "An advanced Treatise on Jigs and Fixture Design". In proceeding International journal of engineering research and technology, Vol.2 Issue 8 August- 2013.

5. K M Viragama, R D Makawama. "A study on Design of fixture for Valve Body for CNC Machine". In proceeding International journal of advance engineering and research development, Volume-1. Issue 12 December-2014.

6. Shrinivas R, Mrs.Manjula, Saira Das Bharadwaj. Design modelling and analysis of standardize hydraulic power pack. In proceeding International journal of research in Engineering and Technology Vol 5.2015. 